\title{
The Role of Novel Molecular Techniques for Tuberculosis Diagnostics in the WHO European Region
}

\author{
Soudeh Ehsani, Martin van den Boom, Christopher Gilpin and Masoud Dara*
}

World Health Organization Office, European Union, Denmark

\begin{abstract}
Tuberculosis and particularly multidrug resistant TB remains a major public health concern in the WHO European Region. In order to reduce the burden of the disease, early, accurate and rapid diagnoses play a crucial role. Sputum smear microscopy that has long been used as the main TB diagnostic method detects TB only with low sensitivity and phenotypic culture-based methods require several weeks and high biosafety laboratory infrastructures. The use of the WHO endorsed rapid molecular method for simultaneous detection of TB and rifampicin resistance detection has promising advantages to overcome these challenges and lead to major advances for early and accurate diagnosis of TB. With better understanding appearing discordances between phenotypic and genotypic methods, as well as the development and implementation of regionally adapted diagnostic algorithms, the precision of result acquisition and interpretation can advance even further.
\end{abstract}

Keywords: Tuberculosis; Multidrug; Microscopy; Diagnosis

\section{Introduction}

Tuberculosis is one of the three leading infectious diseases, HIV and Malaria being the other two, accounting for more than $40 \%$ of all mortality making it to one of the world's deadliest communicable diseases [1]. TB is also the major cause of death among people living with HIV [2-4]. The emergence of drug-resistant TB strains poses further formidable challenges for effective TB control, as it renders diagnosis, treatment and care more complex [5]. About $25 \%$ of the global burden of multidrug resistant (MDR)-TB occurs in the WHO European region and more than half of the world's high MDR-burden countries are in the eastern part of this region [2-4].

The most widely used initial TB diagnostic tool has been sputum smear microscopy with the shortcoming of not being able to (i) detect viable from dead organisms, (ii) differentiate non TB mycobacteria (NTM) from MTB, (iii) drug resistant and drug susceptible form of TB as well as (iv) low sensitivity for TB detection in persons coinfected with HIV. These limitations with microscopy result in delayed diagnosis which contributes to ongoing disease transmission, increased morbidity and mortality [6]. Mycobacterium tuberculosis complex, the causative agent of $\mathrm{TB}$, is a slow growing bacterium with laboratory confirmation and the detection of drug resistance requiring up to several weeks when using culture-based methods.

In order to reduce the burden of $\mathrm{TB}$, there is a need to improve $\mathrm{TB}$ diagnosis including detection of sputum smear negative cases as well as the detection of drug resistant forms particularly M/XDR-TB cases. The WHO endorsed Xpert MTB/RIF assay allows the detection of TB and rifampicin resistance in one cartridge based test in less than two hours with high sensitivity and specificity using similar biosafety precautions as for sputum smear microscopy [1,6-10]. WHO recommends the use of this test as the initial diagnostic test for $\mathrm{TB}$ and rifampicin resistance detection in patients suspected of having TB, MDR-TB, or HIV-associated TB [1,5,7]. Rifampicin resistance detection is based on detecting mutations, predominately in the Rifampicin ResistanceDetermining Region (RRDR), in the gene encoding for the beta subunit of mycobacterial DNA-dependent RNA polymerase $(r p o B)$ of Mycobacterium tuberculosis [11].

However, some recent studies have reported discordant results between genotypic versus phenotypic methods [12-14]. These discordances can be explained by the fact that not every genotypic modification of the relevant genetic area has an equal impact on results acquired by phenotypic resistance tests. Depending on the position and type of the amino-acid substitution as well as the genetic background of the strain - that can vary according to geographical locations - discordances between phenotypic and genotypic test results can arise [12,15-17].

With regard to discordances due to mutations causing elevated fitness cost including disputed mutations resulting in borderline rifampicin resistance, genotypic tests have proven to be more sensitive and reliable as diagnostic tool than phenotypic tests particularly the rapid culture tests $[12-14,17,18]$. Such mutations appear to be clinically relevant causing disease for which first-line treatment is likely to fail [7]. Silent mutations do occur but have so far been reported with very low frequency. Nevertheless, they are a potential cause of false positive rifampicin resistance result $[12,13,19]$. Other mutations responsible for RR located outside the RRDR have also been reported in specific geographical regions mainly from retreated or relapse cases and cannot be detected using the Xpert MTB/RIF assay. In case of mixed Mycobacterium tuberculosis complex infections, depending on the proportion and nature of the mutation, discordance between the two methods has been reported as well [12,20]. Further whole genome sequencing studies on population based collection of TB strains would help to better understand the prevalence of silent mutations and borderline rifampicin resistant strains with mutations in the $r p o B$ gene as well as the role of lineage differences and their impact on rifampicin resistance.

All mentioned reasons for discordance between the methods can

*Corresponding author: Masoud Dara, Senior Advisor, World Health Organization, Denmark, Tel: 4545336993; E-mail: daram@who.int

Received April 29, 2015; Accepted June 16, 2015; Published June 18, 2015

Citation: Ehsani S, Van den Boom M, Gilpin C, Dara M (2015) The Role of Novel Molecular Techniques for Tuberculosis Diagnostics in the WHO European Region. J Med Microb Diagn S3: 006. doi:10.4172/2161-0703.S3-006

Copyright: $\odot 2015$ Ehsani S, et al. This is an open-access article distributed unde the terms of the Creative Commons Attribution License, which permits unrestricted use, distribution, and reproduction in any medium, provided the original author and source are credited. 
Citation: Ehsani S, Van den Boom M, Gilpin C, Dara M (2015) The Role of Novel Molecular Techniques for Tuberculosis Diagnostics in the WHO European Region. J Med Microb Diagn S3: 006. doi:10.4172/2161-0703.S3-006

Page 2 of 2

depend on geographical locations owing to the phylogeography of the pathogen, the prevalence of the disease and its resistance form within human populations $[7,14,21,22]$. Therefore, a geographically well adapted and orchestrated diagnostic algorithm also with regards to disease burden distribution, differences in infrastructure and welfare is crucial in allowing the novel diagnostic tools to develop their full beneficial impact for accurate, early and rapid diagnosis [2,23]. Although there is no perfect "gold standard" method for the detection of resistance to rifampicin, genotypic methods that detect mutations in the $r p o B$ gene are the most rapid and reliable so far for rifampicin resistance. In the WHO European Region, depending on resistance prevalence and patients risk group, the detection of mutations in the $r p o B$ gene should be used to inform the decision to initiate a MDR-TB regimen [7].

The WHO Regional Office for Europe has been implementing the Consolidated Action Plan to prevent and Combat M/XDR-TB 2011-2015, which was endorsed by the WHO Regional Committee in September 2011 [3]. Improving laboratory diagnosis has been prioritized with the establishment of the European TB Laboratory Initiative (ELI). ELI has been working to craft a new diagnostic algorithm with taking the large heterogeneity of the WHO European Region into account that would combine the different types of tests synergistically by targeting different patient groups appropriately $[24,25]$. This will help to make the best use of the available resources by maximizing their respective strengths and mitigating their weaknesses.

\section{References}

1. WHO World Health Organization Global tuberculosis control (2011): epidemiology, strategy, financing. Geneva, Switzerland.

2. (2012) World Health Organization Regional Office for Europe, Copenhagen, Denmark 2012. The European health report: charting the way to well-being.

3. (2013) Roadmap to prevent and combat drug-resistant tuberculosis. European Centre for Disease Prevention and Control/WHO Regional Office for Europe. Tuberculosis surveillance and monitoring in Europe. Stockholm: European Centre for Disease Prevention and Control.

4. (2008) European Centre for Disease Prevention and Control/WHO Regional Office for Europe. Tuberculosis surveillance and monitoring in Europe. Stockholm: European Centre for Disease Prevention and Control.

5. WHO (2008) WHO policy statement: molecular line probe assays for rapid screening of patients at risk of multidrug-resistant tuberculosis.

6. Catharina CB, Nabeta P, Hillemann D, Nicol MP, Shenai S, et al. (2010) Rapid Molecular Detection of Tuberculosis and Rifampin Resistance. N Engl J Med 363: 1005-1015

7. WHO (2014) Rapid implementation of the Xpert MTB/RIF diagnosis test. Technical and operational "How to" practical considerations. World Health Organization document WHO/HTM/TB/20112. WHO, Geneva, Switzerland.

8. Zmak L, Jankovic M, Jankovic VK (2013) Evaluation of Xpert MTB/RIF assay for rapid molecular diagnosis of tuberculosis in a two-year period in Croatia International Journal of Mycobacteriology 2: 179-182.
9. Muñoz L, Moure R, Porta N, Gonzalez L, Guerra R, et al. (2013) Author's personal copyGeneXpert $₫$ for smear-negative pulmonary tuberculosis: does it play a role in low-burden countries? Diagnostic Microbiology and Infectious Disease 75: 325-326.

10. Scott L, Albert H, Gilpin C, Alexander H, DeGruy K, et al. (2014) Multicenter Feasibility Study To Assess External Quality Assessment Panels for Xpert MTB/RIF Assay in South Africa. J Clin Microbiol 52: 2493-2499.

11. Weyer K, Mirzayev F, Migliori GB, Gemert WV, Lia D'Ambrosio, et al. (2013) Rapid molecular TB diagnosis: evidence, policy making and global implementation of Xpert MTB/RIF. Eur Respir J 42: 252-271.

12. Ocheretina O, Escuyer VE, Mabou MM, Royal-Mardi G, Collins S, et al. (2014) Correlation between Genotypic and Phenotypic Testing for Resistance to Rifampin in Mycobacterium tuberculosis Clinical Isolates in Haiti: Investigation of Cases with Discrepant Susceptibility Results. PLoS One 9.

13. Van Deun A, Aung KJM, Hossain A, de Rijk P, Gumusboga M, et al. (2015) Disputed rpoB mutations can frequently cause important rifampicin resistance among new tuberculosis patients. Int J Tuberc Lung Dis 19: 185-190.

14. Van Deun A, Aung KJ, Bola V, Lebeke R, Hossain MA, et al. (2013) Rifampin drug resistance tests for tuberculosis: challenging the gold standard. J Clin Microbiol 51: 2633-2640.

15. Yang B, Koga H, Ohno H, Ogawa K, Fukuda M, et al. (1998) Relationship between antimycobacterial activities of rifampicin, rifabutin and KRM-1648 and rpoB mutations of Mycobacterium tuberculosis. J Antimicrob Chemother 42: 621-628.

16. Campbell EA, Pavlova O, Zenkin N, Leon F, Irschik H, et al. (2005) Structural, functional, and genetic analysis of sorangicin inhibition of. Embo J 24: 674-682.

17. Gagneux S, Long CD, Small PM, Van T, Schoolnik GK, et al. (2006) The competitive cost of antibiotic resistance in Mycobacterium tuberculosis. Science 312: 1944-1946.

18. Van Deun A, Barrera L, Bastian I, Fattorini L, Hoffmann H, et al. (2009) Mycobacterium tuberculosis strains with highly discordant rifampin susceptibility test results. J Clin Microbiol 47: 3501-3506.

19. Adikaram CP, Perera J, Wijesundera SS (2012) Geographical profile of rpoB gene mutations in rifampicin resistant Mycobacterium tuberculosis isolates in Sri Lanka. Microb Drug Resist 18: 525-530.

20. Boehme CC, Nicol MP, Nabeta P, Michael JS, Gotuzzo E, et al. (2011) Feasibility, diagnostic accuracy, and eff ectiveness of decentralised use of the Xpert MTB/RIF test for diagnosis of tuberculosis and multidrug resistance: a multicenter implementation study. Lancet 377: 1495-1505.

21. Gagneux S (2012) Host-pathogen coevolution in human tuberculosis. Philos Trans R Soc Lond B Biol Sci 367: 850-859.

22. Gagneux S, DeRiemer K, Van T, Kato-Maeda M, de Jong BC, et al. (2006) Variable host-pathogen compatibility in Mycobacterium tuberculosis. Proc Natl Acad Sci U S A 103: 2869-2873.

23. ECDC/WHO (2014) Tuberculosis surveillance and monitoring in Europe.

24. Dobler CC, Korver S, Batbayar O, Nyamdulam B, Oyuntsetseg S, et al. (2015) Detection of Drug-Resistant Tuberculosis by Xpert MTB/RIF in Swaziland. N Engl J Med 372: 1181-1182.

25. Siu GK, Zhang Y, Lau TC, Lau RW, Ho PL, et al. (2011) Mutations outside the rifampicin resistance-determining region associated with rifampicin resistance in Mycobacterium tuberculosis. J Antimicrob Chemother 66: 730-733. 